\title{
Comparison of diagnostic accuracy of saline infusion sonohysterography, transvaginal sonography, and hysteroscopy in evaluating the endometrial polyps in women with abnormal uterine bleeding: a systematic review and meta-analysis
}

\author{
Mania Kaveh ${ }^{1}$, Kambiz Sadegi ${ }^{2}$, Morteza Salarzaei ${ }^{3}$, Fateme Parooei ${ }^{3}$ \\ 'Department of Obstetrics and Gynaecology, Zabol University of Medical Sciences, Zabol, Iran \\ ${ }^{2}$ Department of Anaesthesiology and Pain, Zabol University of Medical Sciences, Zabol, Iran \\ ${ }^{3}$ Student Research Committee, Zabol University of Medical Sciences, Zabol, Iran
}

Videosurgery Miniinv 2020; 15 (3): 403-415 DOI: https://doi.org/10.5114/wiitm.2020.93791

\begin{abstract}
Introduction: In women with abnormal uterine bleeding (AUB), endometrial polyps are a frequent finding, and the risk of a focal (pre)malignancy in a polyp is up to $6 \%$. Because of this reported risk, the detection of polyps in these women is important.

Aim: To evaluate and compare the diagnostic accuracy of saline infusion sonohysterography, transvaginal sonography, and hysteroscopy in detecting endometrial polyps in women with AUB.

Material and methods: The searches were conducted by two independent researchers to find the relevant studies published from 1/1/2009 until the end of 30/06/2019. We searched for published literature in English language in MEDLINE, EMBASETM, The Cochrane Library, and Trip database. For literature published in other languages, we searched national databases (Magiran and SID), KoreaMed, and LILACS. The risk of bias of every article was evaluated by using QUADAS-2.

Results: After selection and quality assessment, 11 studies were included. Based on the random effect model the total prevalence of endometrial polyps in women with abnormal uterine bleeding was 38\%. The sensitivity and specificity of saline infusion sonohysterography in diagnosis of endometrial polyps were 0.87 and 0.86 , respectively. The sensitivity and specificity of transvaginal ultrasonography were 0.62 and 0.73 and the sensitivity and specificity of hysteroscopy were 0.92 and 0.85 , respectively.

Conclusions: Although that sonohysterography is a safe and relatively cheap method, which allows ruling out or confirming endometrial polyps, it cannot be replaced with hysteroscopy due to the fact that hysteroscopy combined with biopsy is the gold standard for ruling out malignancies in an endometrial polyp.
\end{abstract}

Key words: abnormal uterine bleeding, sonohysterography, transvaginal sonography, saline infusion sonohysterography.

\section{Introduction}

Abnormal uterine bleeding (AUB) is one of the most common disorders in women of childbearing age. Abnormal uterine bleeding can significantly affect women's personal and social life [1-4]. AUB is defined as the irregularity of the menstrual cycle and includes all changes in the duration, frequency

Address for correspondence

Fateme Parooei, Student Research Committee, Zabol University of Medical Sciences, Zabol, Iran, e-mail: zhn.search@gmail.com 
of menstruation, and the amount of bleeding [5-9]. Although over $30 \%$ of women's referrals to health centres are estimated to be due to AUB, it is worth noting that some patients may not refer to medical centres and clinics $[10,11]$. Perhaps this is why the prevalence of AUB in different studies has been reported to vary from $10 \%$ to $52 \%$ [12-14]. With an estimated prevalence of $24 \%$, endometrial polyps are one of the most common causes of AUB and infertility. They are mostly benign, but sometimes they are associated with malignant and pre-malignant lesions [15]. Hysteroscopy in combination with histopathology is the gold standard for diagnosis and treatment of endometrial polyps [16-19]. Although invasive methods are very helpful in finding the possible causes of abnormal uterine bleeding, they can sometimes be expensive and uncomfortable [20, 21]. Noninvasive methods are applicable to diagnose abnormal uterine bleeding before or after menopause and enable the individual to determine which invasive procedure (e.g. endometrial biopsy, dilatation, curettage, or hysteroscopy) is appropriate [22-26]. Various diagnostic tools are used to diagnose uterine malformations that lead to abnormal uterine bleeding. Among these, transvaginal ultrasonography, saline contrast sonohysterography, and hysteroscopy are commonly used $[27,28]$. Transvaginal ultrasonography is the first screening procedure used to diagnose uterine malformations, while hysteroscopy combined with histopathology is considered as the gold standard in evaluating patients with abnormal uterine bleeding. Although transvaginal ultrasonography is an effective screening test to assess abnormal uterine bleeding caused by endometrial atrophy [29-32], it has a low specificity and a limited sensitivity in evaluating thick, non-homogenous endometrium that can be replaced with saline contrast sonohysterography, which is able to distinguish focal lesions (such as submucosal polyps and myomas). It also provides information on the localisation and extent of sub-endometrial lesions affecting the uterine cavity and makes it possible to select the appropriate surgical procedure for diffuse lesions (such as hyperplasia and cancer) [33-38]. On the other hand, recent investigations have found some new tools for polypectomy using hysteroscopy in an outpatient setting, which can decrease patient discomfort. Also it makes it possible to diagnose and treat at the same time, which can lower the costs
[37, 39-41]. Considering that the risk of focal (pre) malignancy in endometrial polyps in women with $A \cup B$ is $6 \%$ to $4.47 \%$, diagnosis of polyps in these women and knowing which diagnostic tool to use is very important [42-44].

\section{Aim}

The aim of present systematic review and metaanalysis was to evaluate and compare the diagnostic accuracy of saline infusion sonohysterography, transvaginal sonography, and hysteroscopy in evaluating the endometrial polyps in women with AUB.

\section{Material and methods}

The systematic review and meta-analysis was performed based on PRISMA principles. Two independent researchers (HD and MS) carried out the searches to obtain the relevant researches released from 1/1/2009 to 31/06/2019. MEDLINE via PubMed, EMBASETM via Ovid, the Cochrane Library, and Trip database were searched for published literature in English language. National databases (Magiran and SID), KoreaMed, and LILACS were searched for literature released in other languages. The list of the research references found in the search was investigated to assure the saturation of literature (FP). A health sciences librarian with a specialty in systematic review searches via the MESH and open expressions according to the PRESS norms performed the unique search approaches. The outcomes were compared to look for further databases (MS and FP) once the MEDLINE policy was finalised. PROSPERO was also searcged, to discover the latest or current systematic reviews. The keywords employed in the search approach were 'saline contrast sonohysterography' [Mesh], endometrial pathology [Mesh] OR - polyps [Mesh] OR - uterus, [Mesh] sonohysterography, endometrial polyp [Mesh] OR - sonography [Mesh] OR - Uterine abnormalities [Mesh] OR Hysteroscopy [Mesh] OR - transvaginal sonography [Mesh] OR - AUB [Mesh]. In order to identify the published research, the list of prior sources and systematic examinations were also checked (HD and MS).

\section{Eligibility criteria}

The applied inclusion criteria to choose papers were as follows: (a) original retrospective and prospective blinded researches on the transvaginal ul- 
trasonography and saline infusion sonohysterography and hysteroscopy performance for evaluating endometrial polyps women with abnormal uterine bleeding; (b) comprising either a $2 \times 2$ table or data that allowed a $2 \times 2$ table construction; (c) describing the diagnostic criteria for endometrial polyps on transvaginal ultrasonography, hysteroscopy and saline infusion sonohysterography, completely; (d) using hysteroscopy combined with histopathology as the reference standard; and (e) meeting quality standards, as evaluated by the 14-item Quality Assessment of Diagnostic Accuracy Studies (QUADAS2).

\section{Data extraction and risk of bias evaluation}

To assess the participants' characteristics, the data was extracted. The index test consisted of features, such as special equipment and reference standard (organiser of the tests and the interval between them). Also, the data associated with precision diagnosis were extracted. The data were extracted by the first reader (MS). Then, the data were approved by the second reader (HD), who could finish them if they were incomplete.

QUADAS-2 (a modified instrument for quality assessment of diagnostic precision research) assessed the probability of bias in each paper; four probable bias areas were assessed. The first one is the choice of patient (picking up the participants sequentially or randomly). The test conditions are essential for the participants. The bias risk, therefore, is high in the investigations; those suspected of endometrial polyps only were chosen. The second area is the index test (incorrect reading of the index test and correct clarification of detection threshold). A reference standard or "gold standard" (99\% precision, the interpretation disregarding the index test results) is the third area. Flow and timing (the index test receiver's description, the time interval between index tests, and reference standard) is the last domain. The paper was assessed by two reviewers independently via QUADAS-2 criteria (MS, FP). The reviewers debated the article once the independent assessments were done. To achieve a single idea, each domain was discussed. $\kappa$-statistic was applied to measure the reliability of the reviewers for each area.

\section{Statistical analysis}

Pooled measures for sensitivity, specificity, diagnostic odds ratio (DOR), and area under the curves
(AUC) with their 95\% confidence intervals (Cls) were measured via DerSimonian Lair according to the results in the $2 \times 2$ tables [45]. Test summary receiver-operator curves (ROCS) were rebuilt via Moses-Shapiro-Littenberg on the basis of the pooled DOR of each index [46]. The DOR shows the test capability to distinguish appendicitis in this case. A DOR of 1 specifies that the test has no discriminative power. The greater the DOR, the better the imaging mode's diagnostic capacity. A Cochran Q statistic and the $R^{2}$ index were applied to assess heterogeneity between studies. A significant $R^{2}$ index specifies heterogeneity outside the sampling variation. To detect pre-defined sources of heterogeneity, a meta-regression analysis was carried out. The forest plots were built with freeware Meta-DiSc, version 1.4 (http://www.hrc.es/ investigacion/ metadisc-en.htm; Ramon y Cajal Hospital; Madrid, Spain) [47]. To offer a comprehensive analysis, the data associated with the diagnostic accuracy of transvaginal ultrasonography, hysteroscopy, and saline infusion sonohysterography were collected. Certain studies then were meta-analysed for each category; they had a high and low risk of bias in participant selection (according to QUADAS-2 criteria). For each study, according to the true-positive, true-negative, false-positive, as well as false-negative rates, sensitivity, specificity, and positive and negative likelihood ratios (LRs) were calculated. LRs are autonomous from incidence rates, and there is an agreement that a positive $L R>10$ and a negative $L R<0.1$ offer substantial proof of reasonable diagnostic performance [48]. In a single global accuracy measure, the ratio of positive LR to negative LR was joint [49]. Through a bivariate random effect model, summary sensitivity and specificity, positive and negative LRs, as well as diagnostic odds ratios were calculated. The method presumes bivariate normal distributions for the logit transformations of sensitivity and specificity of particular investigations [50, 51]. Furthermore, the hierarchical summary receiver-operating characteristic (ROC) curve was built by specifying the point estimations for each research, the joint ROC curve, and the pooled characteristics with the 95\% confidence and the $95 \%$ prediction region [52].

\section{Results}

\section{The selection of studies}

Based on the search strategy, 1155 studies were selected. After examining the conformity of the 
studies with the required criteria, 11 studies were selected for final review (Figure 1).

\section{The characteristics of the selected studies}

The characteristics of each selected study are shown in Table I. Overall, 1929 patients were studied in 11 studies. Of these 11 studies, 4 (36\%) were retrospective and 7 (64\%) were prospective. The study population included women with abnormal uterine bleeding. The patients ranged in age from 33 to 88 years. An experienced radiologist and, in most cases, an experienced fellow of radiology evaluated the saline infusion sonohysterography, transvaginal sonography, and hysteroscopy of all the studies.

\section{The risk of bias}

The evaluation findings of QUADAS-2 are shown in Figure 2. The findings indicate that there is a risk of bias of evaluation for one parameter. These studies have certain limitations (Figure 2).

\section{Meta-analysis}

Diagnostic accuracy of transvaginal ultrasonography, saline infusion sonohysterography, and hys- teroscopy performance for evaluating the endometrial polyps in women with abnormal uterine bleeding.

Saline infusion sonohysterography in the detection of endometrial polyps in women with abnormal uterine bleeding

For endometrial polyps, the sensitivity and specificity of saline infusion sonohysterography were 0.87 (95\% Cl: $0.82-0.91)$ and 0.86 (95\% Cl: 0.83-0.89), respectively. The diagnostic odds ratio was 52.54 (95\% Cl: 10.62-260). The SROC diagram shows a summary of the estimated sensitivity and specificity and the area below the SROC curve for saline infusion sonohysterography in detecting endometrial polyps in women with abnormal uterine bleeding (Figures 3,4 ). The positive and negative LRs for saline infusion sonohysterography in detecting endometrial polyps in women with abnormal uterine bleeding were 8.20 (95\% Cl: 2.49-27.01) and 0.168 (95\% Cl: $0.077-0.368)$, respectively. A significant heterogeneity was observed for the specificity $\left(R^{2}=93.5 \%\right.$; Cochrane $\left.Q=92.02 ; p<0.001\right)$ and sensitivity $\left(I^{2}=73.1 \%\right.$; Cochrane $Q=22.34$; $p<0.0011)$

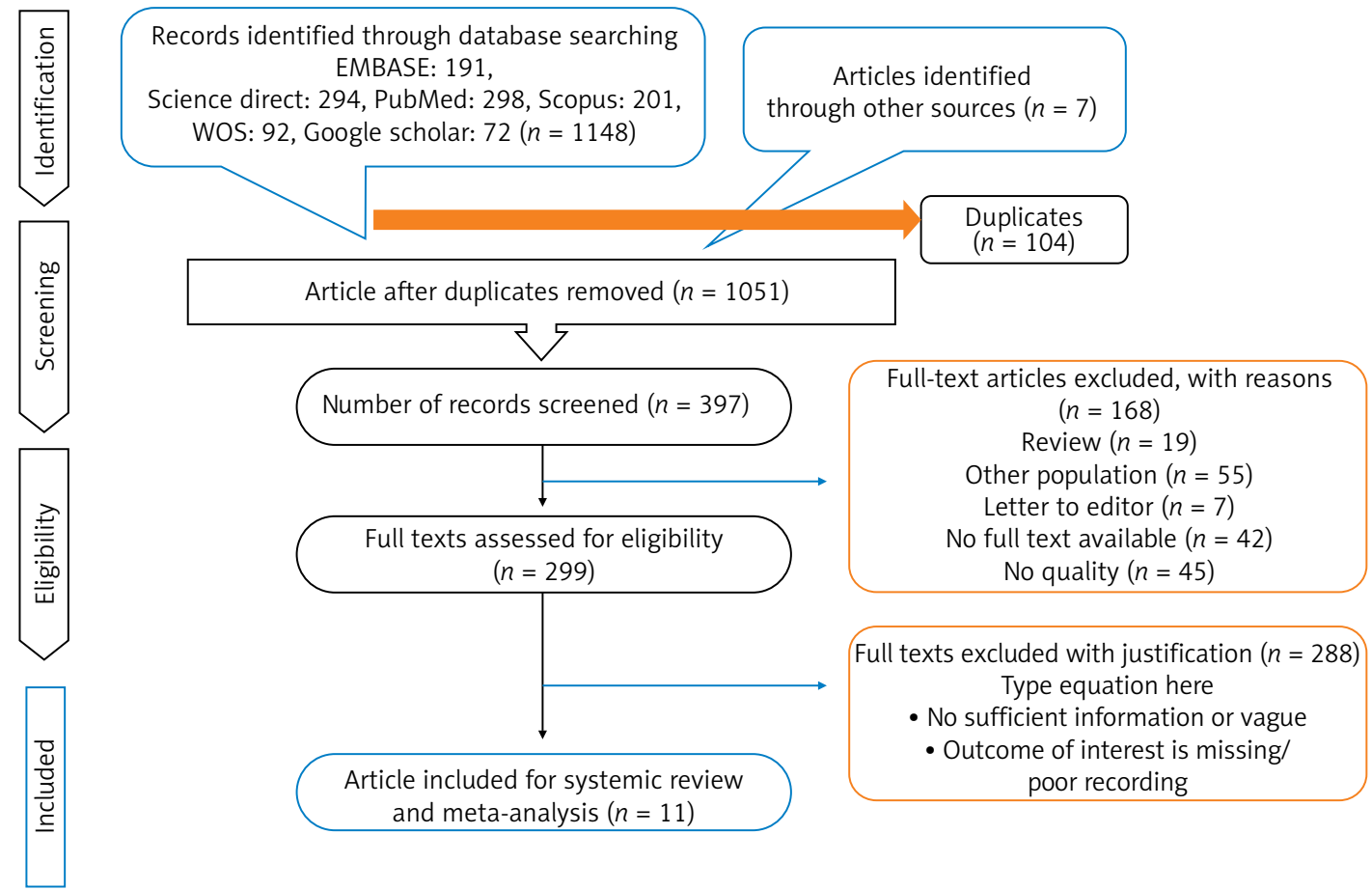

Figure 1. PRISMA flow diagram 
Transvaginal ultrasonography in the detection of endometrial polyps in women with abnormal uterine bleeding

For endometrial polyps in women with abnormal uterine bleeding, the sensitivity and specificity of transvaginal ultrasonography were $0.62(95 \% \mathrm{Cl}$ : $0.57-0.67)$ and 0.73 (95\% Cl: 0.68-0.77), respectively. The diagnostic odds ratio was 0.73 (95\% Cl: $0.68-$ 0.77). The SROC diagram shows a summary of the estimated sensitivity and specificity and the area below the SROC curve for transvaginal ultrasonography in detecting endometrial polyps in women with abnormal uterine bleeding (Figures 3, 4). The positive and negative LRs for transvaginal ultrasonography endometrial polyps in women with abnormal uterine bleeding were 2.27 (95\% Cl: 1.16-4.43) and 0.60 (95\% Cl: $0.38-0.94)$, respectively. A significant heterogeneity was observed for the specificity $\left(I^{2}=95.9 \%\right.$; Cochrane $\left.Q=170.15 ; p<0.0001\right)$ and sensitivity $\left(I^{2}=86.7 \%\right.$; Cochrane $Q=52.69 ; p<$ $0.0001)$. The forest plots for the specificity and sensitivity are shown in Figures 3 and 4.

Hysteroscopy in the detection of endometrial polyps in women with abnormal uterine bleeding

For endometrial polyps in women with abnormal uterine bleeding, the sensitivity and specificity of hysteroscopy were $0.92(95 \% \mathrm{Cl}: 0.89-0.94)$ and 0.85 ( $95 \%$ Cl: 0.81-0.88), respectively. The diagnostic odds ratio was 86.17 (95\% Cl: 26.22-283.19). The SROC diagram shows a summary of the estimated sensitivity and specificity and the area below the SROC curve for hysteroscopy in detecting endometrial polyps in women with abnormal uterine bleeding (Figures 3,4 ). The positive and negative LRs for hysteroscopy in detecting endometrial polyps in women with $a b-$ normal uterine bleeding were 6.11 (95\% Cl: $2.30-$ 16.20) and 0.07 (95\% Cl: 0.012-0419), respectively. A significant heterogeneity was observed for the specificity $\left(I^{2}=90.2 \%\right.$; Cochrane $\left.Q=30.72 ; p<0.0001\right)$ and sensitivity $\left(I^{2}=93.4 \%\right.$; Cochrane $Q=45.46$; $p<0.0001$ ) (Figure 3, Table II).

\section{The subgroup analysis}

\section{Country}

The combined prevalence in two studies in Iran, tweo studies in the UK, and two studies in Turkey for

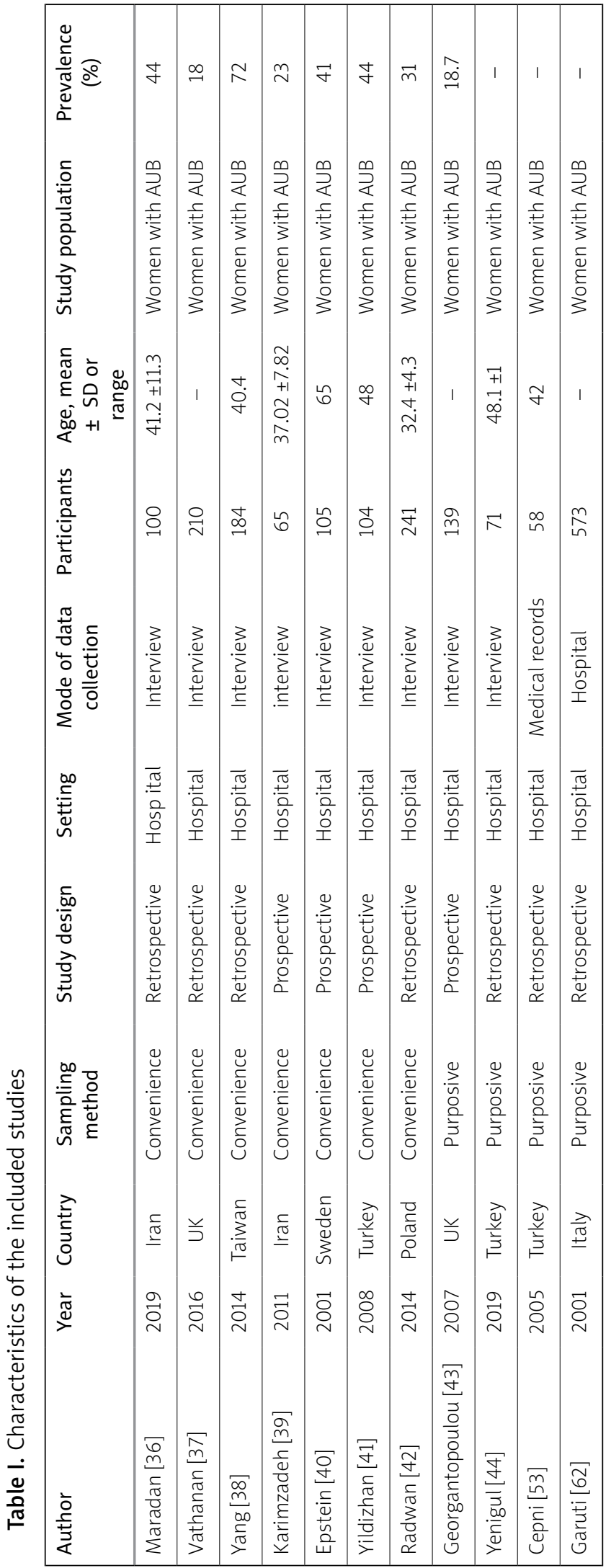



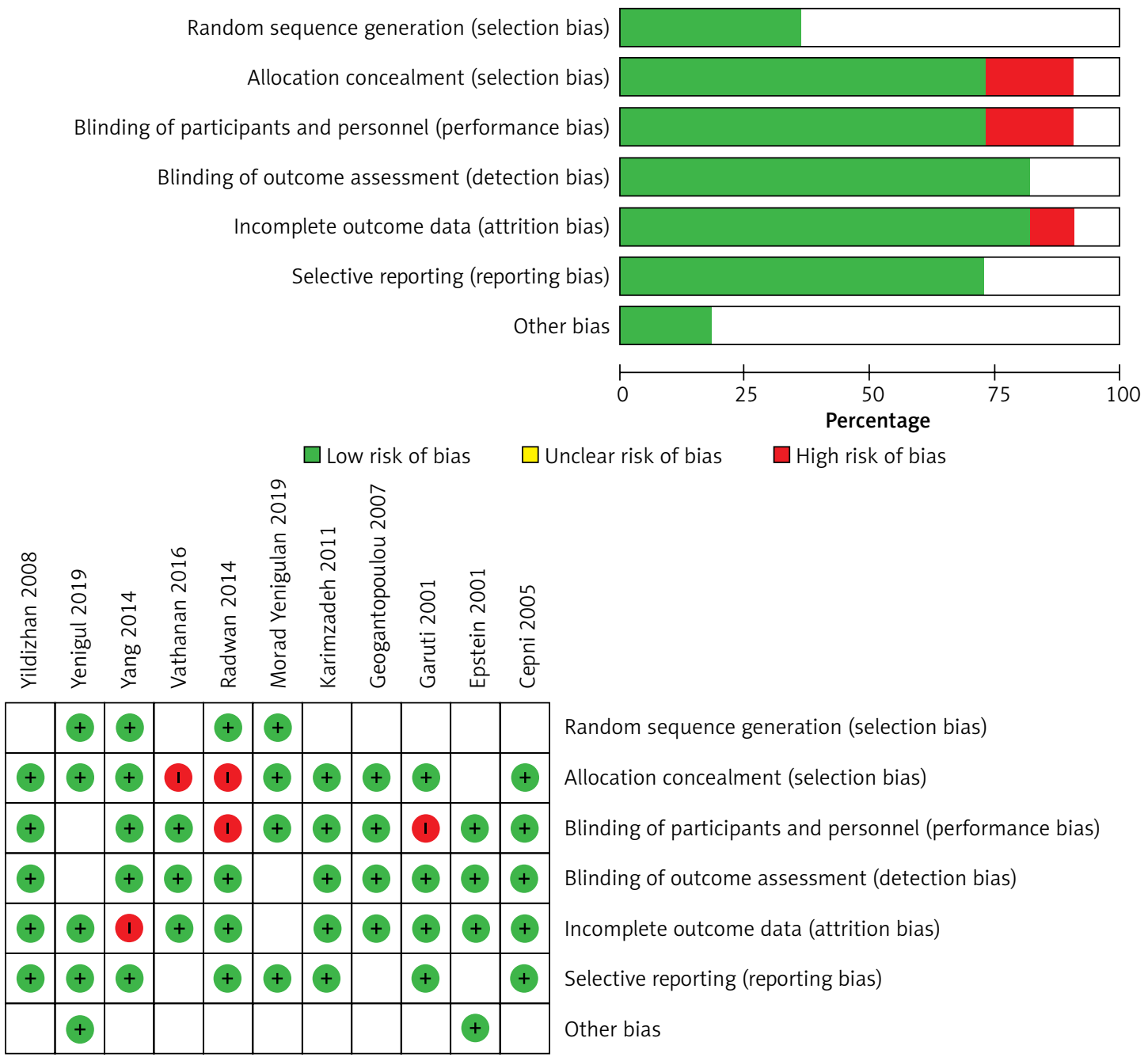

Figure 2. The risk of bias in the studies conducted was measured by using QUADAS-2 tool. The risk of bias shown in Equation 2 of the above image model of each diagram indicates the number and percentage of studies with high (red), medium (yellow), and low (green) risk of bias in four groups of the QUADAS-2 tool

endometrial polyps in women with abnormal uterine bleeding were $46 \%(95 \% \mathrm{Cl}: 35-40.1 \%), 18.2 \%$ (95\% Cl: $25.2-36.8 \%)$, and $47.9 \%(95 \% \mathrm{Cl}: 40.3-$ $55.5 \%$ ), respectively (Figure 5 ).

Meta-analysis of prevalence of endometrial polyps in women with abnormal uterine bleeding

Based on the random effect model, the total prevalence of endometrial polyps in women with abnormal uterine bleeding was 38\% (95\% Cl: 35-41\%) (Figure 4).
Meta-regression findings based on the publication year, age, and prevalence of endometrial polyps in women with abnormal uterine bleeding

The studies' meta-regression was according to the association between prevalence of endometrial polyps in women with abnormal uterine bleeding and the year of publication of the studies. It showed that the overall rate of endometrial polyps in women with abnormal uterine bleeding was lower in newer studies than in the older ones (Figure 6). But there was no statistically significant linear trend in univariate meta-regression to explain effect size variation by publication year of 
A

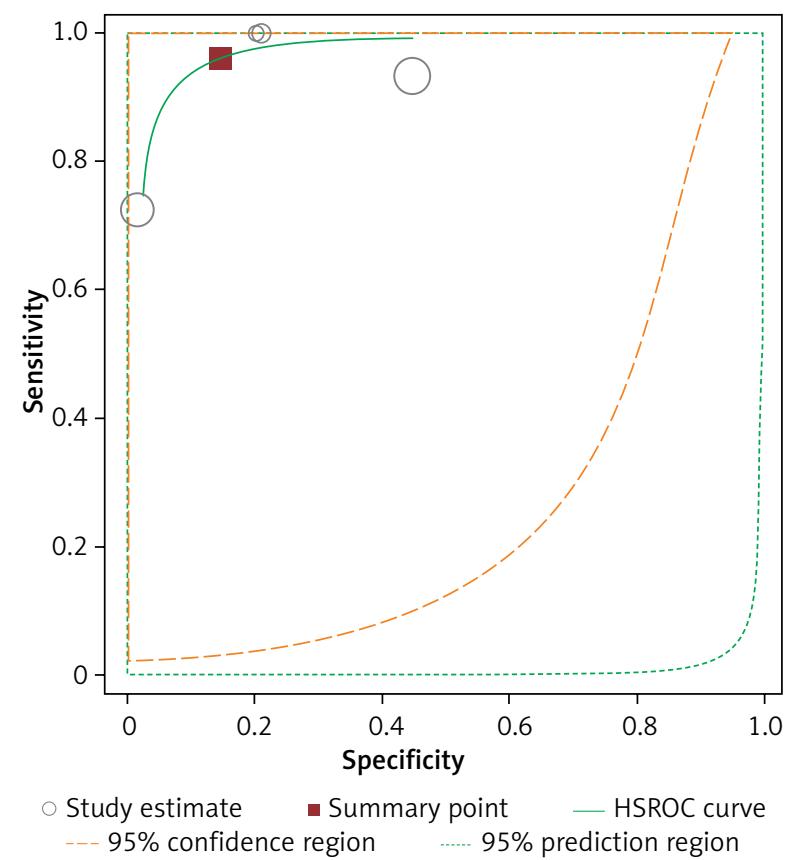

C

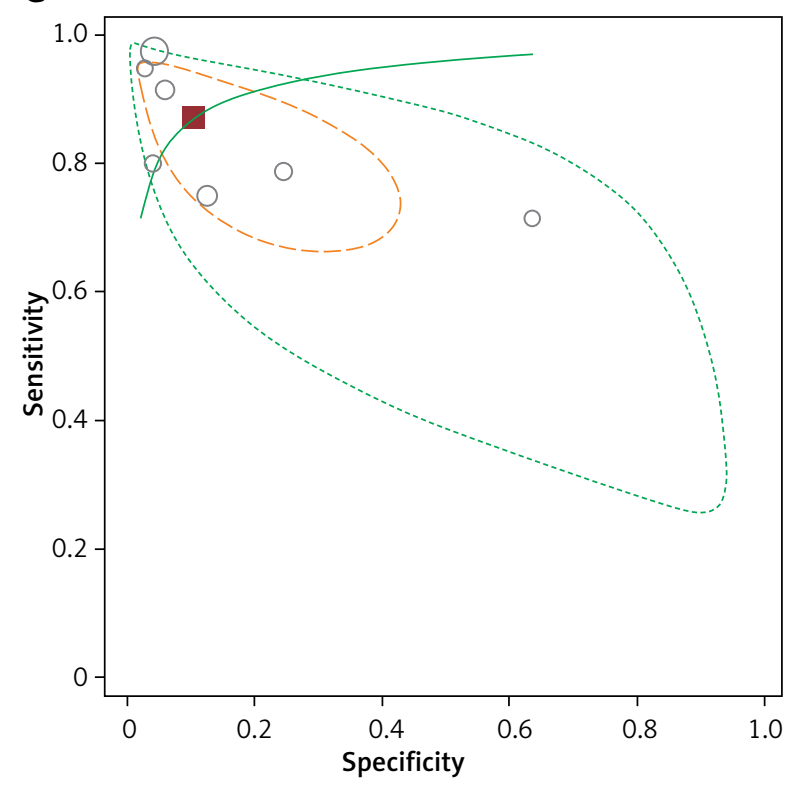

- Study estimate - Summary point_ HSROC curve $95 \%$ confidence region $\quad$..... 95\% prediction region

study with coefficient $=-0.56(95 \% \mathrm{Cl}:-0.03,0.02)$, $p=0.62$ and mean age of patients with coefficient $=$ 0.0016 (95\% Cl: $-0.01,0.01), p=0.82$.

\section{Meta-regression}

The results of meta-regression showed that none of the evaluated variables (see above) explained the
B

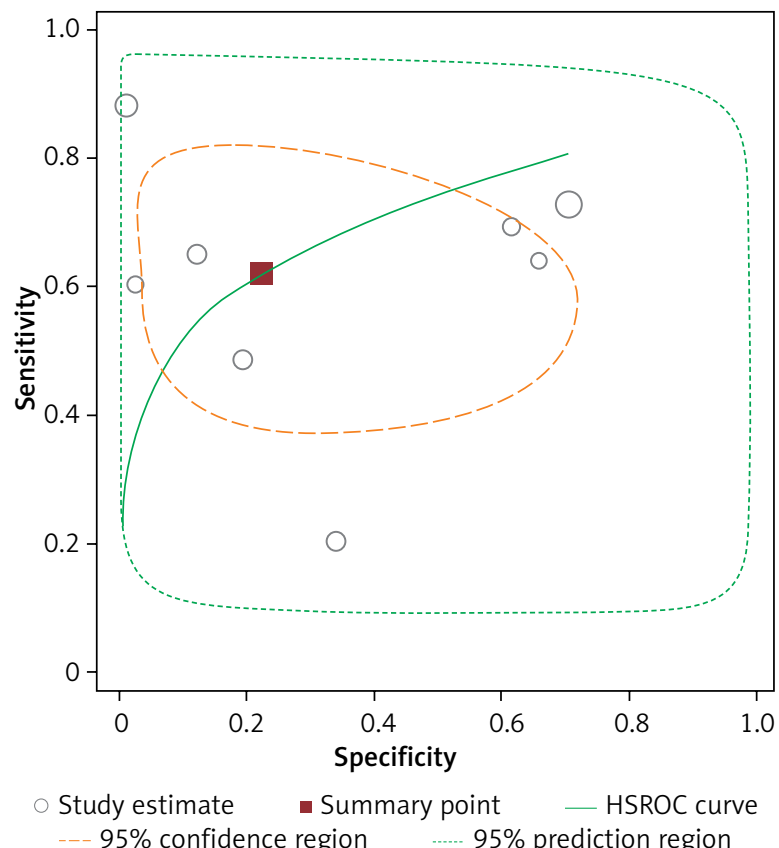

Figure 3. Hierarchical summary receiver (HSROC) curve for hysteroscopy (A), transvaginal ultrasonography (B), and saline infusion sonohysterography (C) for diagnosing endometrial polyps in women with abnormal uterine bleeding

heterogeneity. The summary curve of the receiver system performance characteristic for the diagnostic performance of saline infusion sonohysterography (A), transvaginal ultrasonography (B), and hysteroscopy in detecting endometrial polyps in women with abnormal uterine bleeding, is shown in Figure 3. The Fagan nomogram shows that TVS findings suspected of endometrial polyps increase the probability 
Study ID

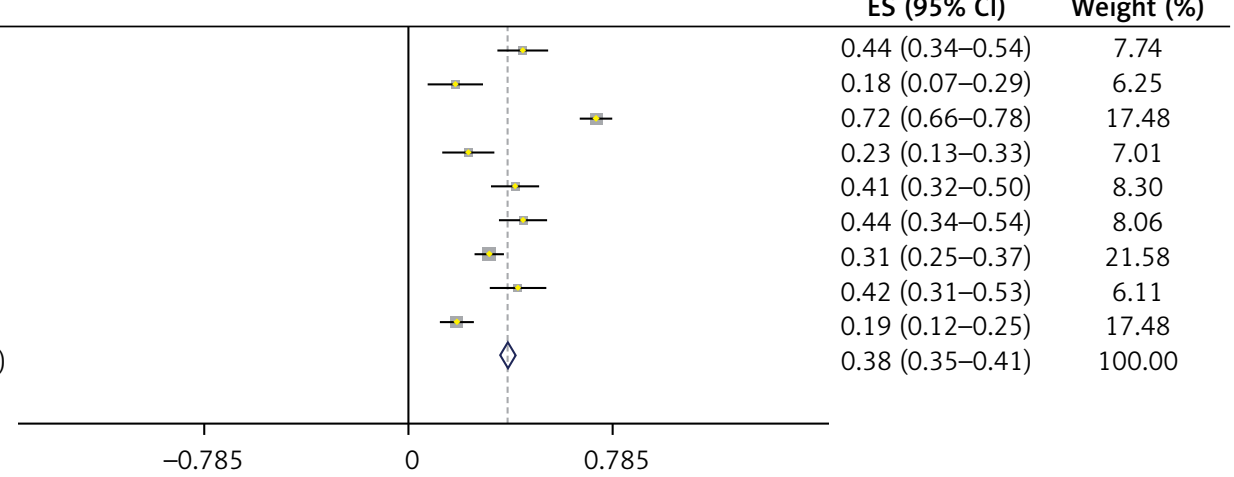

Figure 4. Meta-analysis of the overall prevalence of endometrial polyps in women with abnormal uterine bleeding

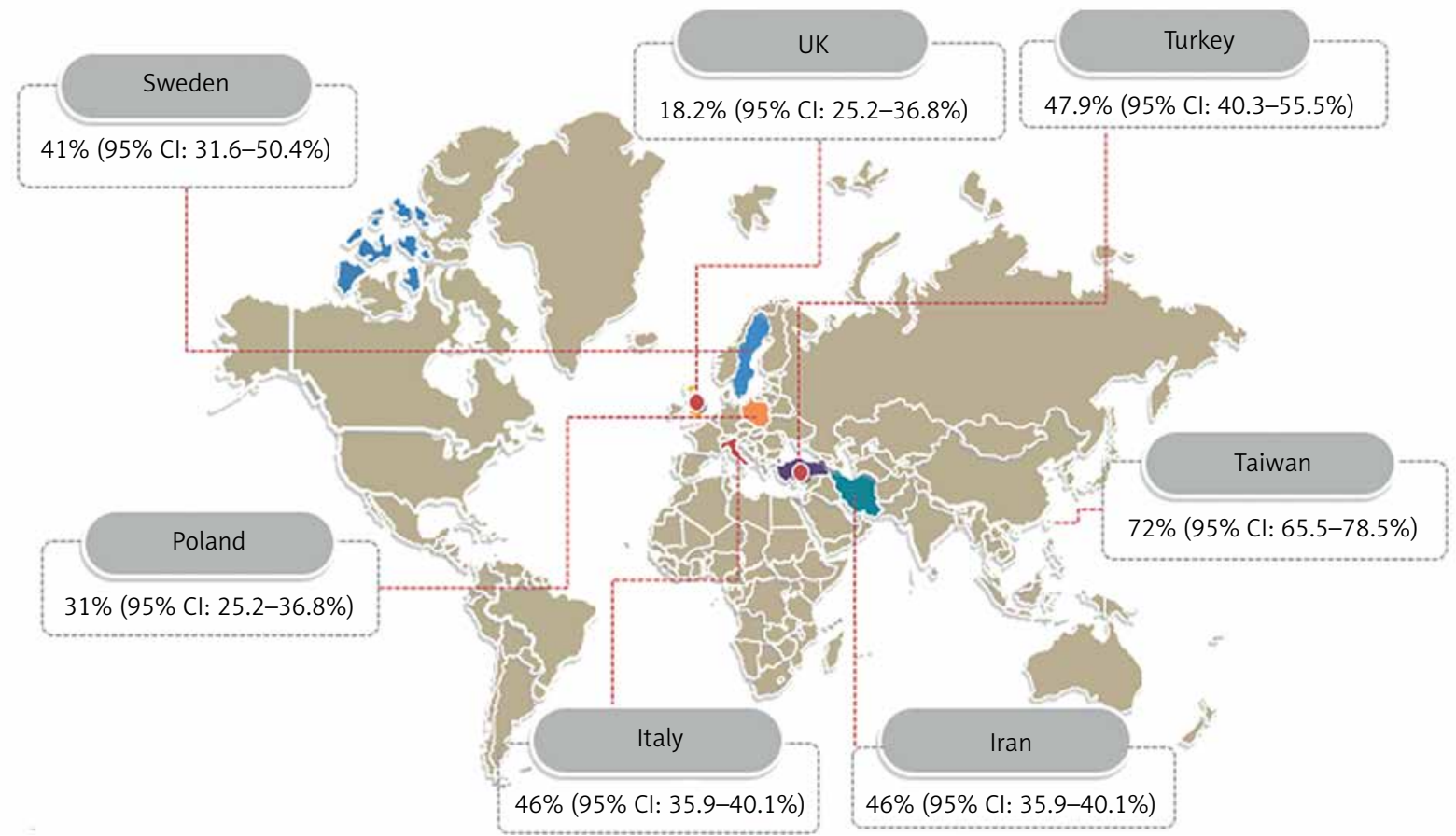

Figure 5. Pooled prevalence of endometrial polyps in women with abnormal uterine bleeding by country

of abnormal uterine bleeding from $50 \%$ to $69.4 \%$, while normal ultrasound findings decrease the pretest probability from $50 \%$ to $37.5 \%$ (Figure 7 ). SIS findings suspected of endometrial polyps increase the probability of abnormal uterine bleeding from $50 \%$ to $89.1 \%$, while normal SIS findings decrease the pretest probability from $50 \%$ to $14.4 \%$ (Figure 7 ). Also hysteroscopy findings suspected of endometrial polyps increase the probability of abnormal uterine bleeding from $50 \%$ to $85.9 \%$, while normal hysteroscopy findings decrease the pretest probability from $50 \%$ to $41.2 \%$

\section{Discussion}

Histological examination is still the gold standard for uterine cavity pathologies such as endometrial polyps. The evaluation of abnormal uterine bleeding is traditionally based on histological diagnosis, established either with dilatation and curettage or endometrial biopsy. However, these diagnostic procedures are invasive and they may not detect all of the endometrial abnormalities if performed alone [53]. In this systematic review and meta-analysis we compared the diagnostic accuracy obtained through easily ad- 
A

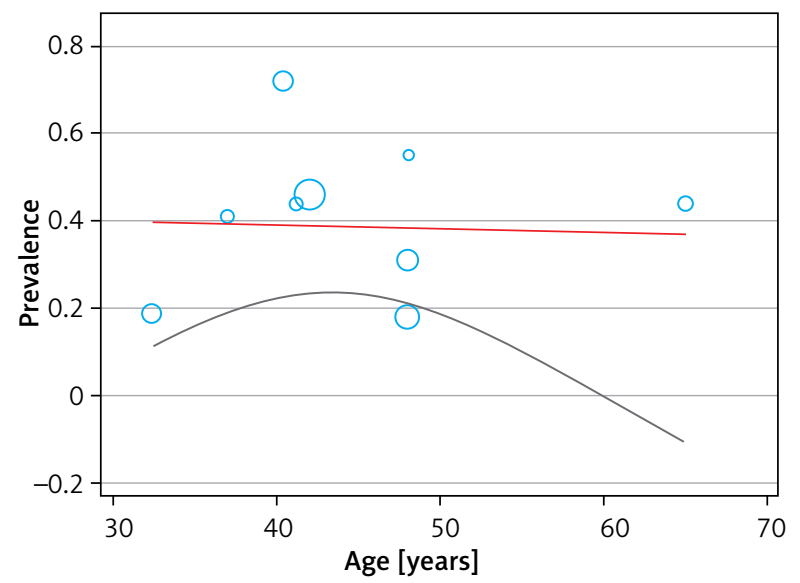

B

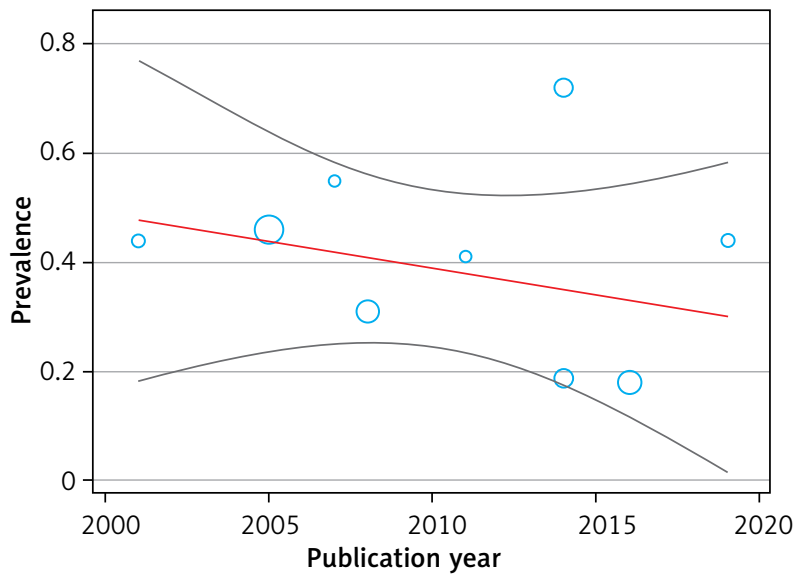

Figure 6. Meta-regression between age (A), publication year of study (B), and prevalence of endometrial polyps in women with abnormal uterine bleeding

ministered, inexpensive, and noninvasive methods that do not lead to complications and can be easily accepted by women, with the results obtained through invasive methods that are still considered to be the gold standard. The pooled sensitivity, specificity, and diagnostic odds ratio of TVS in women with AUB were $62.1 \%$ and $77.6 \%$, respectively, to detect polyps, while histopathology was the reference standard. Kamel et al., in their study, reported a $64.5 \%$ sensitivity and a $75.5 \%$ specificity for TVS using the same the reference standard [54], which is partially consistent with the present systematic review and meta-analysis. Zhu et al., in a more recent study, reported $67 \%$ sensitivity and $96 \%$ specificity for TVS in the diagnosis of endometrial polyps [55]. These results reveal that TVS is helpful in the assessment of cases with abnormal uterine bleeding; however, polyps are often missed, particularly when cervical or cornual in location. Furthermore, it cannot differentiate endometrial thickening from polyps in most cases [56,57]. SISH is another evaluating method that makes distension in the uterine cavity to visualise the endometrial surface [58]. In addition, it causes less pain, costs less, and can be performed more easily and faster with greater safety compared to hysteroscopy [59]. We found that SISH has a sensitivity of $87.9 \%$ and a specificity of $92.2 \%$ in the detection of endometrial polyps. Our results are consistent with the previous systematic review conducted by Vroom et al., which reported a sensitivity of $86.5 \%$ and specificity of $91.1 \%$ for SISH in diagnosis of endometrial polyps [60]. Also, de Kroon et al. in their meta-analysis reported that the feasibility of saline contrast hysterosonography was $93 \%$ (95\% Cl:
92-94\%) [61]. Garuti et al. also reported a sensitivity of $95.3 \%$ and a specificity of $95.4 \%$ for hysteroscopy in the diagnosis of endometrial polyps [62]. However, provided that the only way to rule out the risk of malignancy is through hysteroscopy and biopsy, SISH can be used as a method to stratify patients with AUB in order to go for more diagnostic work up and treatment with hysteroscopy. Nevertheless, hysteroscopy is an exceptionally sensitive method, allowing the exclusion of intracavitary pathology as well as treatment in the same sitting with proper tissue biopsy from the abnormal area, which can be of help in proper treatment planning. We calculated a $0.92(95 \% \mathrm{Cl}$ : $0.89-0.94)$ sensitivity and a specificity of $0.85(95 \% \mathrm{Cl}$ : 0.81-0.88) for hysteroscopy in diagnosis of endometrial polyps. Also, there has been great progress in using smaller endoscopes and new systems that mean hysteroscopy is available even without any anaesthesia [63].

The strength of this review is that we included in the meta-analysis all available studies with data specifically on women with AUB. This study also has some limitations. The first is the risk of publication bias and possibility of missing eligible studies; these concerns apply to all systematic reviews. We attempted to obviate this risk by performing an extensive search with a clinical librarian and by systematically checking cross-references. The second limitation is that we were able to identify only a small number of eligible studies. Moreover, the number of included patients was low in each study. Another limitation is the risk of bias in patient selection and flow. A change in prevalence could affect 
A

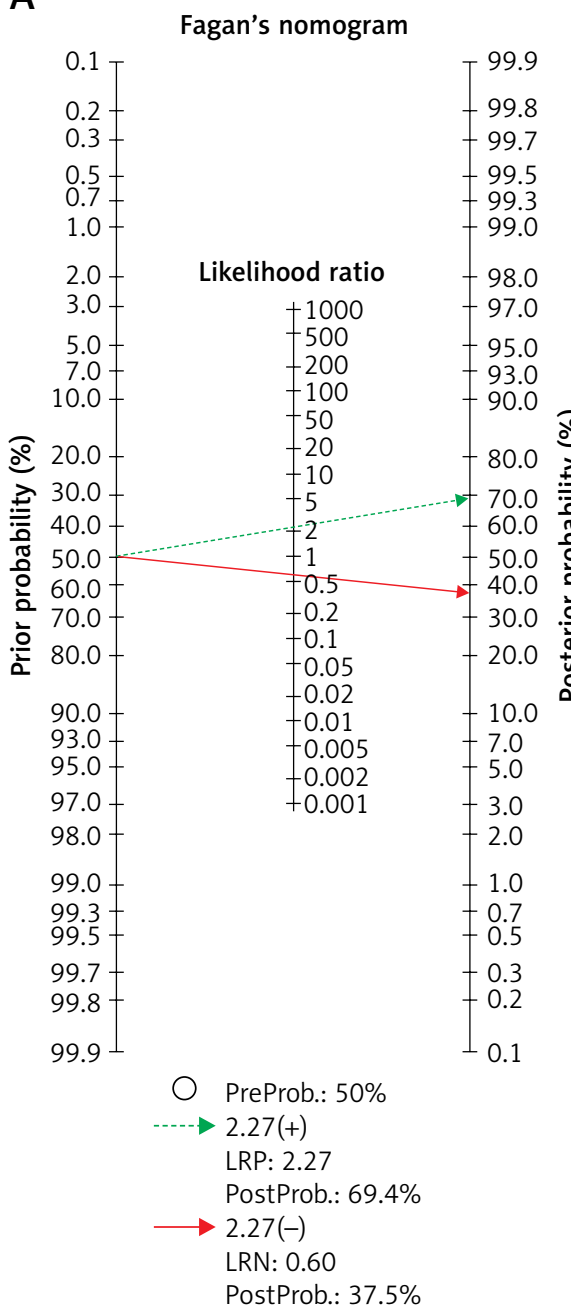

B

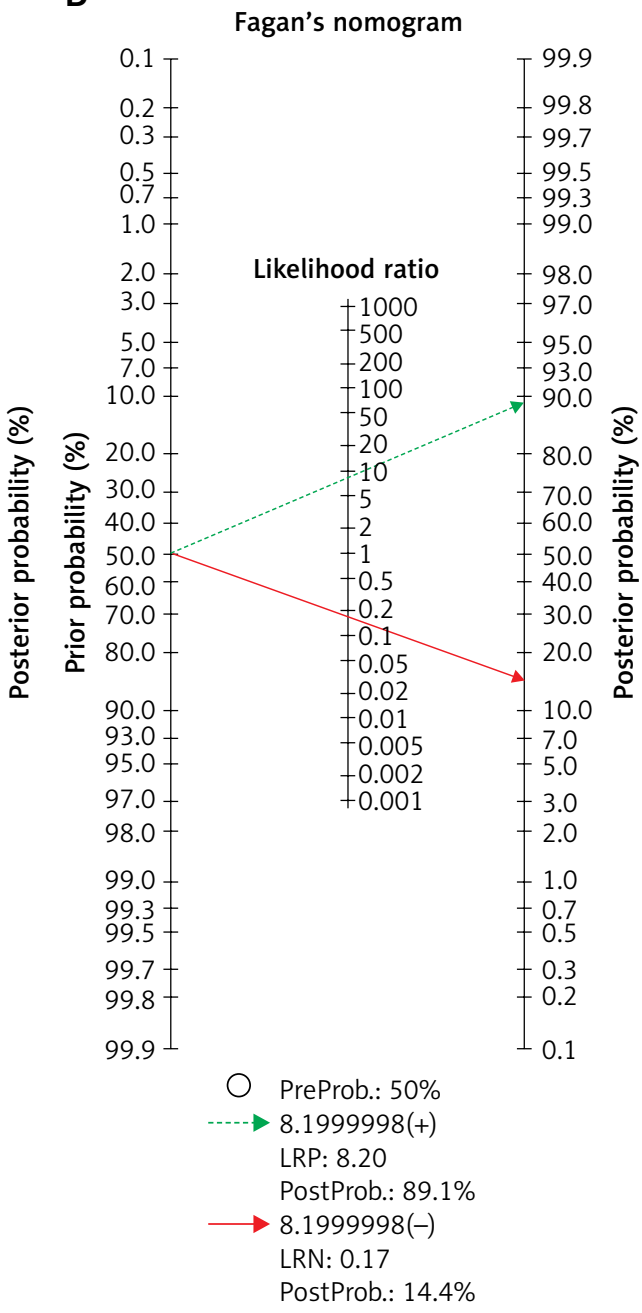

C

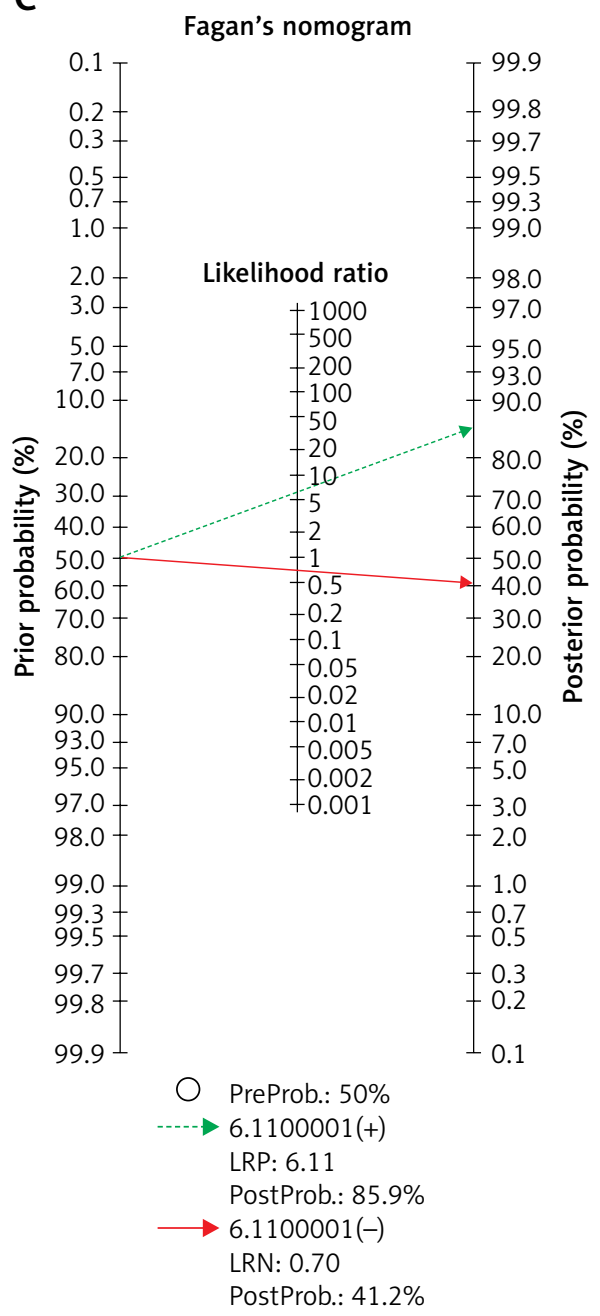

Figure 7. Fagan's nomogram for the calculation of post-test probabilities. A pre-test probability of $50 \%$ for all three diagnostic tools was fixed, which was estimated by the number of symptomatic cases in selected studies. A - TVS had a post-test probability of $69.4 \%$. For SIS (B) the post-test probability was $89.1 \%$, and hysteroscopy (C) had a post-test probability of $85.9 \%$. If this patient tests positive, the post-test probability that she truly has dengue would be $37.5 \%$ (A) or 14.4 (B) or 41.2 (C) (solid line in red). On the other hand, if patient tests negative, the post-test probability that she truly has endometrial polyp would be $69.4 \%$ (A) or $89.1 \%$ (B) or 85.9 (C) (blue dotted line). The results were obtained by the following calculations: pretest odds $=$ prevalence $/ 1-$ prevalence; post-test odds $=$ pretest odds $\times L R-(L R+)$; post-test probability $=$ post test odds $/ 1+$ post-test odds

$L R$ - likelihood ratio.

the diagnostic accuracy, mainly the positive and negative predictive values, but has little influence on the sensitivity and specificity.

\section{Conclusions}

The findings show that a diagnosis established on the basis of SIS results is almost identical to one made after performing hysteroscopy. TVUS may fail to detect endometrial polyps, and in these patients TVUS alone cannot reliably exclude organic causes of AUB. Considering all these results, although sonohysterography is a safe and relatively cheap method that allows for ruling out or confirming endometrial polyps, it cannot be replaced with hysteroscopy due 
Table II. The diagnostic value of saline infusion sonohysterography, transvaginal sonography, and hysteroscopy in women with AUB

\begin{tabular}{|lccc|}
\hline Parameter & TVS & SIS & Hysteroscopy \\
\hline Sensitivity $(95 \% \mathrm{Cl})$ & $0.62(0.57-0.67)$ & $0.87(0.82-0.91)$ & $0.92(0.89-0.94)$ \\
\hline Specificity $(95 \% \mathrm{Cl})$ & $0.73(0.68-0.77)$ & $0.86(0.83-0.89)$ & $0.85(0.81-0.88)$ \\
\hline PLR $(95 \% \mathrm{Cl})$ & $2.27(1.16-4.43)$ & $8.20(2.49-27.01)$ & $6.11(2.30-16.20)$ \\
\hline NLR $(95 \% \mathrm{Cl})$ & $0.60(0.38-0.94)$ & $0.168(0.077-0.368)$ & $0.07(0.012-0.419)$ \\
\hline DOR $(95 \% \mathrm{Cl})$ & $0.73(0.68-0.77)$ & $52.54(10.62-260)$ & $86.17(26.22-283.19)$ \\
\hline PPV & 0.67 & 0.79 & 0.84 \\
\hline NPV & 0.68 & 0.92 & 0.95 \\
\hline AUC-SROC & 0.6735 & 0.9337 & 0.9511 \\
\hline P & $89 \%$ & $88.6 \%$ & $94 \%$ \\
\hline Q index & 0.6320 & 0.8695 & 0.8919 \\
\hline
\end{tabular}

to the fact that hysteroscopy combined with biopsy is the gold standard for ruling out malignancies in an endometrial polyp.

\section{Conflict of interest}

The authors declare no conflict of interest.

\section{References}

1. Short J, Sharp B, Elliot N, et al. Does the addition of saline infusion sonohysterography to transvaginal ultrasonography prevent unnecessary hysteroscopy in premenopausal women with abnormal uterine bleeding? Aust N Zeal J Obstet Gynaecol 2016; 56: 432-5.

2. Inoue T, Kitajima M, Taniguchi K, Masuzaki H. Three-dimensional saline-infusion sonohysterography is useful for the identification of endometrial polyp. J Obstet Gynaecol Res 2016; 42: 855-9.

3. Whitaker L, Critchley HO. Abnormal uterine bleeding. Best Pract Res Clin Obstet Gynaecol 2016; 34: 54-65.

4. Bradley LD, Gueye NA. The medical management of abnormal uterine bleeding in reproductive-aged women. Am J Obstet Gynecol 2016; 214: 31-44.

5. Shea AK. Comparison of saline infusion sonohysterography and transvaginal ultrasound in detection of endometrial polyps. EC Gynaecol 2018; 7: 260-4.

6. Grimbizis GF, Tsolakidis D, Mikos T, et al. A prospective comparison of transvaginal ultrasound, saline infusion sonohysterography, and diagnostic hysteroscopy in the evaluation of endometrial pathology. Fertil Steril 2010; 94: 2720-5.

7. Bingol B, Gunenc MZ, Gedikbasi A, et al. Comparison of diagnostic accuracy of saline infusion sonohysterography, transvaginal sonography and hysteroscopy in postmenopausal bleeding. Arch Gynecol Obstet 2011; 284: 111-7.
8. Moschos E, Ashfaq R, Mclntire DD, et al. Saline-infusion sonography endometrial sampling compared with endometrial biopsy in diagnosing endometrial pathology. Obstet Gynecol 2009; 113: 881-7.

9. La GS, Blasi I, Gallinelli A, et al. Diagnostic accuracy of sonohysterography and transvaginal sonography as compared with hysteroscopy and endometrial biopsy: a prospective study. Minerva Ginecol 2011; 63: 421-7.

10. Karsidag AY, Buyukbayrak EE, Kars B, et al. Transvaginal sonography, sonohysterography, and hysteroscopy for investigation of focal intrauterine lesions in women with recurrent postmenopausal bleeding after dilatation and curettage. Arch Gynecol Obstet 2010; 281: 637-43.

11. Mathew M, Gowri V, Rizvi SG. Saline infusion sonohysterography - an effective tool for evaluation of the endometrial cavity in women with abnormal uterine bleeding. Acta Obstet Gynecol Scand 2010; 89: 140-2.

12. Yang T, Pandya A, Marcal L, et al. Sonohysterography: principles, technique and role in diagnosis of endometrial pathology. World J Radiol 2013; 5: 81-7.

13. Vitner D, Filmer S, Goldstein I, et al. A comparison between ultrasonography and hysteroscopy in the diagnosis of uterine pathology. Eur J Obstet Gynecol Reprod Biol 2013; 171: 143-5.

14. Shokeir T, Abdelshaheed M. Sonohysterography as a first-line evaluation for uterine abnormalities in women with recurrent failed in vitro fertilization-embryo transfer. Fertil Steril 2009; 91: 1321-2.

15. Miranda SM, Gomes MT, Silva ID, Girao MJ. Endometrial polyps: clinical and epidemiological aspects and analysis of polymorphisms. Rev Bras Ginecol Obstet 2010; 32: 327-33.

16. Reeves MF, Goldstein RB, Jones KD. Communication of adenomyosis with the endometrial cavity: visualization with saline contrast sonohysterography. Ultrasound Obstet Gynecol 2010; 36: 115-9. 
17. Aboulghar MM, Shoeir IK, Momtaz M, et al. A comparative study of 2-dimensional sonohysterography versus 3-dimensional sonohysterography in infertile patients with uterine cavity lesions and abnormalities. Middle East Fertility Soc J 2011; 16: 67-71.

18. Van Den Bosch T, Van Schoubroeck D, Luts J, et al. Effect of gel-instillation sonography on Doppler ultrasound findings in endometrial polyps. Ultrasound Obstet Gynecol 2011; 38: 355-9.

19. Kasraeian M, Asadi N, Ghaffarpasand F, Karimi AA. Value of transvaginal ultrasonography in endometrial evaluation of non-bleeding postmenopausal women. Climacteric 2011; 14: 126-31.

20. Sconfienza LM, Lacelli F, Caldiera V, et al. Three-dimensional sonohysterography for examination of the uterine cavity in women with abnormal uterine bleeding: preliminary findings. J Ultrasound 2010; 13: 16-21.

21. Kucur SK, Temizkan O, Atis A, et al. Role of endometrial power Doppler ultrasound using the international endometrial tumor analysis group classification in predicting intrauterine pathology. Arch Gynecol Obstet 2013; 288: 649-54.

22. Feitosa IM, Feitosa HN, Carvalho FH, et al. Comparison between transvaginal ultrasonography and sonohysterography in the assessment of patients with abnormal uterine bleeding. Radiol Brasil 2011; 44: 156-62.

23. Özdemir S, Çelik Ç, Gezginç K, et al. Evaluation of endometrial thickness with transvaginal ultrasonography and histopathology in premenopausal women with abnormal vaginal bleeding. Arch Gynecol Obstet 2010; 282: 395-9.

24. da Silva Wanderley M, Álvares MM, Vogt MD, Sazaki LM. Accuracy of transvaginal ultrasonography, hysteroscopy and uterine curettage in evaluating endometrial pathologies. Rev Bras Ginecol Obstet 2016; 38: 506-11.

25. Godoy Junior CE, Antunes Junior A, Morais SS, et al. Accuracy of sonography and hysteroscopy in the diagnosis of premalignant and malignant polyps in postmenopausal women. Rev Bras Ginecol Obstet 2013; 35: 243-8.

26. Yantapant A. Comparison of the accuracy of transvaginal sonog raphy and hysteroscopy for the diagnosis of endometrial polyps at Rajavithi Hospital. J Med Assoc Thai 2012; 95 Suppl: S92-7.

27. Nieuwenhuis LL, de Vaate MAB, Hehenkamp WJ, et al. Diagnos tic and clinical value of 3D gel installation sonohysterography in addition to 2D gel installation sonohysterography in the assessment of intrauterine abnormalities. Eur J Obstet Gynecol Reprod Biol 2014; 175: 67-74.

28. El-khayat W, Sleet ME, Mahdi EY. Comparative study of transvaginal sonography and hysteroscopy for the detection of pathological endometrial lesions in women with perimenopausal bleeding. Middle East Fertil Soc J 2011; 16: 77-82.

29. Luterek K, Szymusik I, Bartkowiak R, Wielgos M. Sonohysterography in peri-and postmenopausal women with abnorma uterine bleeding or abnormal endometrial appearance. Neuro Endocrinol Letters 2014; 35: 287-300.

30. Rahimi S, Marani C, Renzi C, et al. Endometrial polyps and the risk of atypical hyperplasia on biopsies of unremarkable endometrium: a study on 694 patients with benign endometrial polyps. Int J Gynecol Pathol 2009; 28: 522-8.
31. Ozer A, Ozer S, Kanat-Pektas M. Correlation between transvaginal ultrasound measured endometrial thickness and histopathological findings in Turkish women with abnormal uterine bleeding. J Obstet Gynaecol Res 2016; 42: 573-8.

32. Negm SM, Kamel RA, Abuhamila FA. Three-dimensional sonohysterography compared with vaginoscopic hysteroscopy for evaluation of the uterine cavity in patients with recurrent implantation failure in in vitro fertilization cycles. J Minim Invasive Gynecol 2012; 19: 503-8.

33. Shen L, Wang Q, Huang W, et al. High prevalence of endometrial polyps in endometriosis-associated infertility. Fertil Steril 2011; 95: 2722-4.

34. Jokubkiene L, Sladkevicius P, Valentin L. Appearance of the endometrium at saline contrast sonohysterography in the luteal phase of the menstrual cycle: a prospective observational study. Ultrasound Obstet Gynecol 2015; 45: 339-45.

35. Bhaduri M, Tomlinson G, Glanc P. Likelihood ratio of sonohysterographic findings for discriminating endometrial polyps from submucosal fibroids. J Ultrasound Med 2014; 33: 149-54.

36. Moradan S, Darzi SN, Ghorbani R. Diagnostic value of saline infusion sonohysterography for detecting endometrial focal lesion. Pan Afr Med J 2019; 33: 211.

37. Vathanan V, Armar NA. A comparative observational study of the use of saline uterine hydrosonography for the diagnosis and assessment of uterine cavity lesions in women. Int J Reproduct Med 2016; 2016: 9317194.

38. Yang PY, Wu JL, Wu PW, et al. Accuracy of transvaginal ultrasonography for detecting intrauterine lesions at a Taiwan Medical Center: a correlation with ultrasound and hysteroscopic histopathology. J Med Ultrasound 2014; 22: 37-42.

39. Karimzadeh MA, Firouzabadi RD, Goharzad F. Diagnostic value of saline contrast sonohysterography comparing with hysteroscopy for detecting endometrial abnormalities in women with abnormal uterine bleeding. Iran J Reproduct Med 2011; 9: 199-202.

40. Epstein E, Ramirez A, Skoog L, Valentin L. Transvaginal sonography, saline contrast sonohysterography and hysteroscopy for the investigation of women with postmenopausal bleeding and endometrium > 5 mm. Ultrasound Obstet Gynecol 2001; 18: 157-62.

41. Yildizhan B, Yildizhan R, Ozkesici B, Suer N. Transvaginal ultrasonography and saline infusion sonohysterography for the detection of intra-uterine lesions in pre-and post-menopausal women with abnormal uterine bleeding. J Int Med Res 2008; 36: 1205-13.

42. Radwan P, Radwan M, Kozarzewski M, et al. Evaluation of sonohysterography in detecting endometrial polyps - 241 cases followed with office hysteroscopies combined with histopathological examination. Videosurgery Miniinv 2014; 9: 344-50.

43. Georgantopoulou C, Simm A, Roberts M. Transvaginal saline hysterosonography: a comparison with local anaesthetic hysteroscopy for the diagnosis of benign lesions associated with menorrhagia. Gynecol Surg 2008; 5: 27-34.

44. Yenigul NN, Yilmaz FY, Bahat N, Yilmaz SK. The comparison of transvaginal ultrasonography and hysteroscopy in women with abnormal uterine bleeding: a single center experience. Ann Med Res 2019; 26: 1112-7. 
45. DerSimonian R, Laird N. Meta-analysis in clinical trials. Control Clin Trials 1986; 7: 177-88.

46. Moses LE, Shapiro D, Littenberg B. Combining independent studies of a diagnostic test into a summary ROC curve: data-analytic approaches and some additional considerations. Stat Med 1993; 12: 1293-316.

47. Zamora J, Abraira V, Muriel A, et al. Meta-DiSc: a software for meta-analysis of test accuracy data. BMC Med Res Methodol 2006; 6: 31.

48. Deville WL, Buntinx F, Bouter LM, et al. Conducting systematic reviews of diagnostic studies: didactic guidelines. BMC Med Res Methodol 2002; 2: 9.

49. Glas AS, Lijmer JG, Prins MH, et al. The diagnostic odds ratio: a single indicator of test performance. J Clin Epidemiol 2003; 56: 1129-35.

50. Arends LR, Hamza TH, van Houwelingen JC, et al. Bivariate random effects meta-analysis of ROC curves. Med Decis Making 2008; 28: 621-38.

51. Reitsma JB, Glas AS, Rutjes AW, et al. Bivariate analysis of sensitivity and specificity produces informative summary measures in diagnostic reviews. J Clin Epidemiol 2005; 58: 982-90.

52. Rutter CM, Gatsonis CA. A hierarchical regression approach to meta-analysis of diagnostic test accuracy evaluations. Statist Med 2001; 20: 2865-84

53. Cepni I, Ocal P, Erkan S, et al. Comparison of transvaginal so nography, saline infusion sonography and hysteroscopy in the evaluation of uterine cavity pathologies. Aust N Z J Obstet Gynaecol 2005; 45: 30-5.

54. Kamel HS, Darwish AM, Mohamed SA. Comparison of trans vaginal ultrasonography and vaginal sonohysterography in the detection of endometrial polyps. Acta Obstet Gynecol Scand 2000; 79: 60-4.

55. Zhu H, Fu J, Lei H, et al. Evaluation of transvaginal sonography in detecting endometrial polyps and the pregnancy outcome following hysteroscopic polypectomy in infertile women. Exp Ther Med 2016; 12: 1196-200.

56. Romano F, Cicinelli E, Anastasio P, et al. Sonohysterography versus hysteroscopy for diagnosing endouterine abnormalities in fertile women. Int J Gynaecol Obstet 1994; 45: 253-60.

57. Stadtmauer L, Grunfeld L. The significance of endometrial filling defects detected on routine transvaginal sonography. J UItrasound Med 1995; 14: 169-72.

58. Tur-Kaspa I, Revelli A, Stadtmauer LA, Cohen DP. Sonohysterography $(\mathrm{SHG})$ in reproductive medicine. InL Ultrasound Imaging in Reproductive Medicine. Stadtmauer LA, Tur-Kaspa I (eds). Springer 2019; 199-210.

59. Fadl SA, Sabry AS, Hippe DS, et al. Diagnosing polyps on transvaginal sonography: is sonohysterography always necessary? Ultrasound Q 2018; 34: 272-7.

60. Vroom AJ, Timmermans A, Bongers MY, et al. Diagnostic accuracy of saline contrast sonohysterography in detecting endometrial polyps in women with postmenopausal bleeding: sys tematic review and meta-analysis. Ultrasound Obstet Gynecol 2019; 54: 28-34.

61. de Kroon CD, de Bock GH, Dieben SW, Jansen FW. Saline contrast hysterosonography in abnormal uterine bleeding: a sys- tematic review and meta-analysis. BJOG Int J Obstet Gynaecol 2003; 110: 938-47.

62. Garuti G, Sambruni I, Colonnelli M, Luerti M. Accuracy of hysteroscopy in predicting histopathology of endometrium in 1500 women. J Am Assoc Gynecol Laparosc 2001; 8: 207-13.

63. Nappi L, Sorrentino F, Angioni S, et al. Feasibility of hysteroscopic endometrial polypectomy using a new dual wavelengths laser system (DWLS): preliminary results of a pilot study. Arch Gynecol Obstet 2017; 295: 3-7.

Received: 12.01.2020, accepted: 23.02.2020. 